\title{
EFFECT OF DYEING PARAMETERS ON DYEING OF COTTON FABRICS WITH FLUORO CHLORO PYRIMIDENE REACTIVE DYES
}

\author{
Abu Naser Md. Ahsanul Haque \\ Lecturer, Department of Textile Engineering, BGMEA University of Fashion \& Technology, Dhaka, Bangladesh
}

\begin{abstract}
Effects of electrolyte, alkali, liquor ratio and temperature were observed on dyeing of cotton fabric with Fluoro Chloro Pyrimidene (FCP) Dyes. For this experiment single joursey knitted fabrics were taken. The selected dyestuffs were Drimarene Yellow K2R (DYK), Drimarene Red K8B (DRK) and Drimarene Blue K2RL (DBK). $1 \%$ on the weight of fabric (owf) of each dye was considered for producing 9 combined shades on 9 fabric samples. Isothermal exhaust method was followed for dyeing. To observe the effect of a particular parameter, that one was varied while other parameters kept constant. The dyed samples were tested in a reflectance spectrophotometer (datacolor 650) to get the CIELAB coordinates ( $L^{*}, a^{*}$ and $\left.b^{*}\right)$. The color values $(K / S)$ of the samples were calculated by Kubelka-Munk equation and from that value the strength\% were determined. The results show that DRK and DBK were positively influenced by the increase of electrolyte and temperature though DYK was negatively influenced. All over depth of shade was increasing with the increase of electrolyte, alkali and temperature and 1:20 liquor ratio was found more suitable than 1:10 and 1:30.
\end{abstract}

Keywords: Electrolyte, Alkali, Shade, Liquor ratio, Temperature.

\section{INTRODUCTION}

Bi-functional reactive dyes are known for better exhaustion and fixation properties as they have higher probability to be attracted to the fiber due to double reactive group. They also double their chance to react with fiber and stay in it as an integral part. FCP dyes contain two different halogen groupsfluorine and chlorine. Among the halogens from fluorine to iodine, the chlorine group is favored commercially as its reactivity is moderate among those four. Fluoride group has least reactivity as its bond energy is far higher than chloride $(\mathrm{F}=102 \mathrm{kcal} / \mathrm{g}, \mathrm{Cl}=77 \mathrm{kcal} / \mathrm{g})$ [6]. But in combination of those, a highly reactive dye can be obtained which reactivity lies between MFT and DCT dyes [7].

Dyeing of reactive dyes depends upon different parameters like electrolyte, alkali, liquor ratio and temperature. Generally exhaustion of a reactive dye depends upon electrolyte concentration and reactivity of a dye increases with alkali and dyeing temperature. A highly reactive dye has higher probability to react with fiber but also possess strong chances to get hydrolyzed. That is why the behavior of any dyestuff in different parameters should be studied for getting the optimum results from the process.

Several researchers worked on the influence of dyeing parameters on dyeing with reactive dye. Miljkovic, N. M. et al [1] studied on the effect of dyeing parameter on dyeing with vinyl sulphone dyes. They measured the CIELAB coordinates of the dyed samples and in conclusion suggested that shortening of dyeing time with a reduction of salt can give a better output. On the other hand Saeed, Q. et al [2] worked with four monoazo reactive dyes and observed their effect in different parameters. Exhaustion percentages were found in a range of $65 \%-85 \%$ for those monoazo dyes and they also had good fastness properties.

Another researcher Arzu, H. F. M. et. al [5] analyzed the effect of process parameters on cotton dyeing with reactive dye and got a wide range of application for different reactive dyes. Dalal, M. M. et. al. [3] studied on some bi-functional reactive dyes. They calculated dye bath exhaustion and fixation by absorbance spectroscopy. Those bifunctional dyes showed medium to good substantivity in dye bath. Sultana, R. et.al. [4] performed some laboratory trials with Drimarine Yellow CL2R, Drimarine Red CL5B and Drimarine Blue CL2RL dyes and found almost similar dye extinction coefficient and also good fixation yields for all.

This experimental work has tried to describe the influence of electrolyte, alkali, liquor ratio and temperature on a trichromatic shade matching with FCP dyes. For that reason the CIELAB coordinates were analyzed here to understand the relation of those parameters with the tone of a target shade.

\section{MATERIALS \& METHODS}

\subsection{Materials \& Sample Preparation}

Single jersey scoured and bleached cotton fabric was taken for this experiment. The specifications of the fabric are listed in Table 1 . 
Table 1: Specification of the fabric

\begin{tabular}{|c|c|}
\hline Parameters & Scoured-Bleached Cotton fabric \\
\hline Structure & Single joursey \\
\hline WPI & 50 \\
\hline CPI & 44 \\
\hline Yarn count & $26 \mathrm{Ne}$ \\
\hline Stitch length & $2.54 \mathrm{~mm}$ \\
\hline GSM $\left(\mathrm{g} / \mathrm{m}^{2}\right)$ & 166 \\
\hline
\end{tabular}

9 pieces of fabric samples were taken for dyeing, each one weights 10 gram. They were named as S1, S2, S3, S4, S5, S6, S7, S8 and S9 respectively. All the samples were dyed with $1 \%$ owf Drimarene Yellow K2R (DYK), 1\% owf Drimarene Red K8B (DRK) and 1\% owf Drimarene Blue K2RL (DBK). The sample S1 was dyed with $75 \mathrm{~g} / \mathrm{L}$ glauber salt (electrolyte) and $7.5 \mathrm{~g} / \mathrm{L}$ soda ash (Alkali) in $1: 10$ liquor ratio at $60^{\circ} \mathrm{C}$ temperature. For sample S2 and S3 salt amount was raised to $150 \mathrm{~g} / \mathrm{L}$ and $225 \mathrm{~g} / \mathrm{L}$ respectively keeping the other parameters unchanged. For S4 and S5 soda ash amounts were $15 \mathrm{~g} / \mathrm{L}$ and $22.5 \mathrm{~g} / \mathrm{L}$ and other parameters were same as S1. For S6 and $\mathrm{S} 7$, liquor ratios were 1:20 and 1:30 and other parameters were same as S1. For the dyeing of S8 and S9 also the parameters were like S1, only dye bath temperatures were different- $40^{\circ} \mathrm{C}$ and $80^{\circ} \mathrm{C}$ respectively. Isothermal exhaust method was followed for dyeing.

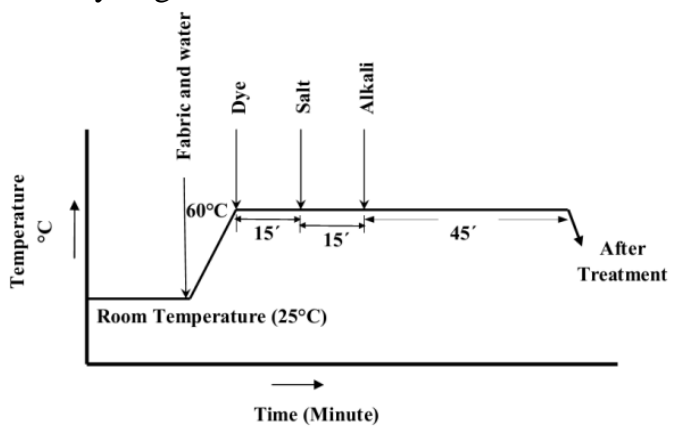

Fig 1: Dyeing curve

The laboratory dyeing machine had the programmed temperature maintaining system and has specially designed dye vessels with a septum by which chemicals were added during the dyeing process. The dyeing process was continued for 45 minutes after the addition of alkali. The temperature versus time curve of dyeing is shown in Figure 1. Only for S8 and S9, the dyeing temperatures were different. After treatment of those dyed samples were done according to the flow chart-

$$
\begin{gathered}
\text { Hot wash }\left(80^{\circ} \mathrm{C}, 10 \text { minutes }\right) \\
\downarrow \\
\text { Neutralization }(0.5 \mathrm{~g} / \mathrm{L} \text { acetic acid }) \\
\downarrow
\end{gathered}
$$

Soap wash ( $1 \mathrm{~g} / \mathrm{L}$ Sandopur SN, $95^{\circ} \mathrm{C}, 15$ minutes $)$

$$
\downarrow
$$$$
\text { Squeezing }
$$$$
\downarrow
$$

Drying $\left(60^{\circ} \mathrm{C}, 30\right.$ minutes $)$

\subsection{Sample Analysis Procedure}

The dried samples were tested in a reflectance spectrophotometer (datacolor 650) with D65 light. The color measurement readings in terms of opponent colors, red-green $\left(a^{*}\right)$, yellow-blue $\left(b^{*}\right)$ and lightness $\left(\mathrm{L}^{*}\right)$ were measured from the instrument. The color strength $(\%)$ of the samples was determined by taking $\mathrm{S} 1$ as the reference $(100 \%$ color strength). Following formula was used for the calculation:

$$
\% \text { Strength }=\frac{K / S_{(\text {sample })}}{K / S_{(\text {standard })}} \times 100
$$

Here $K / S$ is the color value which is calculated from KubelkaMunk equation:

$$
\% \text { Reflectance }=\frac{(\mathbf{1}-\boldsymbol{R})^{2}}{2 \boldsymbol{R}} \times 100
$$

Where $R$ is the spectral reflectance of a colored sample at a wavelength of maximum absorption (where the reflection is minimum).

The results obtained for different electrolyte amount are put in Table 2. Results for different amount of alkali are put in Table 3. Results found for applying different liquor ratios are put in Table 4 and for different temperatures are put in Table 5.

Table 2: CIELAB coordinates for different salt amount

\begin{tabular}{|c|c|c|c|c|}
\hline Amount of electrolyte & $L^{*}$ & $a^{*}$ & $b^{*}$ & $\%$ Strength \\
\hline $75 \mathrm{~g} / \mathrm{L}$ & 33.01 & 8.09 & 1.95 & 100 \\
\hline $150 \mathrm{~g} / \mathrm{L}$ & 32.28 & 8.40 & 1.68 & 105.1 \\
\hline $225 \mathrm{~g} / \mathrm{L}$ & 30.96 & 9.37 & 1.64 & 115.7 \\
\hline
\end{tabular}

Table 3: CIELAB coordinates for different alkali amount

\begin{tabular}{|c|c|c|c|c|}
\hline Amount of alkali & $L^{*}$ & $a^{*}$ & $b^{*}$ & \% Strength \\
\hline $7.50 \mathrm{~g} / \mathrm{L}$ & 33.01 & 8.09 & 1.95 & 100 \\
\hline $15.00 \mathrm{~g} / \mathrm{L}$ & 32.23 & 7.93 & 1.81 & 105.6 \\
\hline $22.50 \mathrm{~g} / \mathrm{L}$ & 31.55 & 8.59 & 1.72 & 110.8 \\
\hline
\end{tabular}

Table 4: CIELAB coordinates for different liquor ratios

\begin{tabular}{|c|c|c|c|c|}
\hline $\mathrm{M}(\mathrm{gm}): \mathrm{L}(\mathrm{ml})$ & $L^{*}$ & $a^{*}$ & $b^{*}$ & $\%$ Strength \\
\hline $1: 10$ & 33.01 & 8.09 & 1.95 & 100 \\
\hline $1: 20$ & 32.41 & 7.72 & 1.89 & 104.4 \\
\hline $1: 30$ & 34.23 & 8.02 & 1.31 & 90.7 \\
\hline
\end{tabular}

Table 5: CIELAB coordinates for different temperatures

\begin{tabular}{|c|c|c|c|c|}
\hline Temperature & $L^{*}$ & $a^{*}$ & $b^{*}$ & $\%$ Strength \\
\hline $40^{\circ} \mathrm{C}$ & 35.05 & 7.61 & 2.69 & 95.6 \\
\hline $60^{\circ} \mathrm{C}$ & 33.01 & 8.09 & 1.95 & 100 \\
\hline $80^{\circ} \mathrm{C}$ & 32.25 & 8.66 & 1.44 & 114.0 \\
\hline
\end{tabular}


The effects of electrolyte, alkali, liquor ratio and temperature on 9 trichromatic shades of FCP dyed cotton fabric were than analyzed. S1, S2, S3 were considered for electrolytes, S1, S4, S5 were considered for alkali, S1, S6, S7 were considered for liquor ratio and $\mathrm{S} 1, \mathrm{~S} 8, \mathrm{~S} 9$ were considered for temperature.

\section{RESULTS \& DISCUSSION}

\subsubsection{Effect of Electrolyte}

Figure 2 represents the effect of electrolyte concentration on FCP dye fabric. $L^{*}$ decreases with the increase of salt which indicates that the darkness of color also increasing. Positive $a^{*}$ value means the redness of a shade which is actually the opposite of green. And green is actually the combination of blue and yellow. Again positive $b^{*}$ is the yellowness of the shade which is actually the opposite of blue.

Figure 2 shows that bigger amount of electrolyte made effects on the uptake of DRK significantly. Electrolyte had the least effect on DYK as $b^{*}$ was decreasing with the increase of electrolyte. Alternately it can be said that tone of DBK was increasing with the increase of electrolyte.

All over color strength of the shade was increasing which has shown in Table 2.

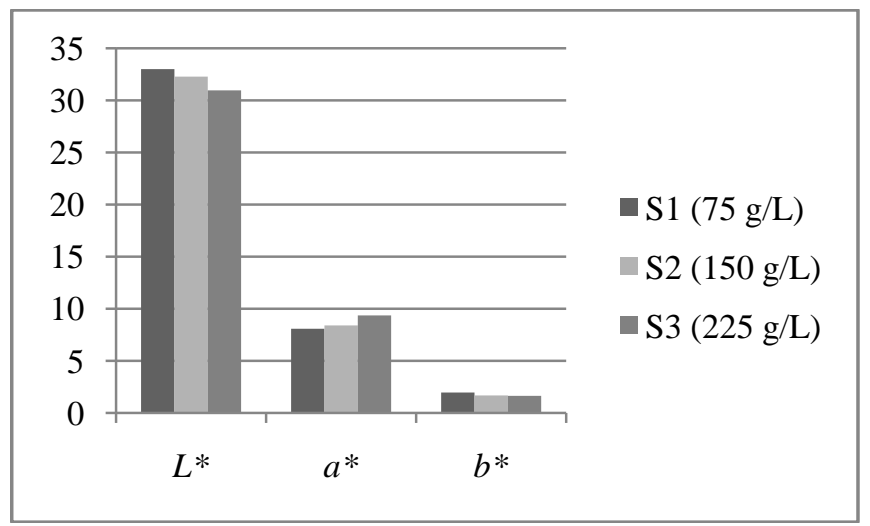

Fig 2: Effect of electrolyte (glauber salt) concentration

\subsubsection{Effect of Alkali}

Figure 3 represents the effect of alkali concentration on FCP dye fabric. Here almost similar kind of result was found. $L^{*}$ decreases with the increase of alkali which indicates that dyes had got opportunity to react with fiber due to presence of more alkali. So the shade became darker. The strength\% values in Table 3 are also supporting this decision. Increase of $a^{*}$ was not fluent with the increase of alkali amount. But $b^{*}$ was always decreasing with the increase of alkali. But changes in yellow were not so much significant. So alkali had a very little effect on these FCP dyes though higher amount of alkali influenced on overall color strength.

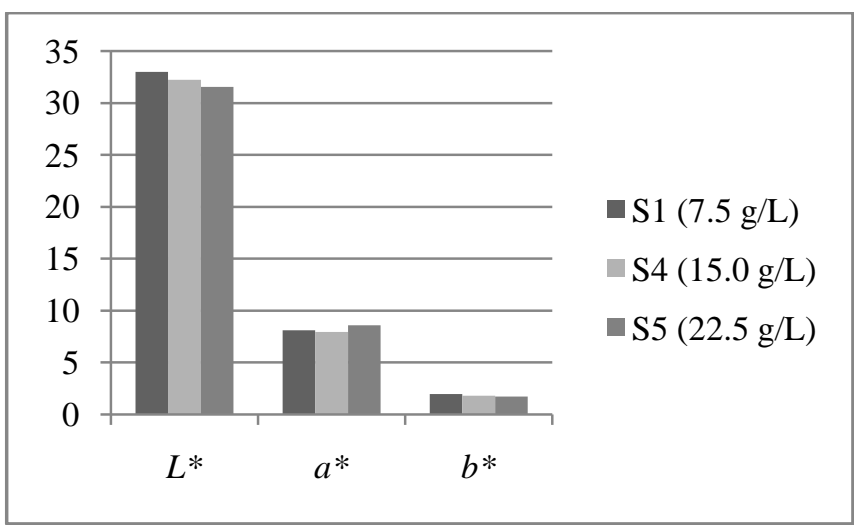

Fig 3: Effect of alkali (Soda ash) concentration

\subsubsection{Effect of Liquor Ratio}

Figure 4 represents the effect of liquor ratio on cotton dyeing with FCP dyes. For 1:20 liquor ratio the lightness $\left(L^{*}\right)$ of the fabric was least. And Table 4 shows that it had the highest color strength at that liquor ratio. It is due to the distribution of dyestuffs which may have occurred properly in 1:20. A small liquor ratio (1:10) was insufficient for proper distribution of total 3\% owf FCP dyes. And the bigger one (1:30) was more than sufficient. So dyes were spread out in large liquor and a low uptake was the result. The value $a^{*}$ was less in 1:20 and $b^{*}$ was decreasing with the increase of liquor ratio.

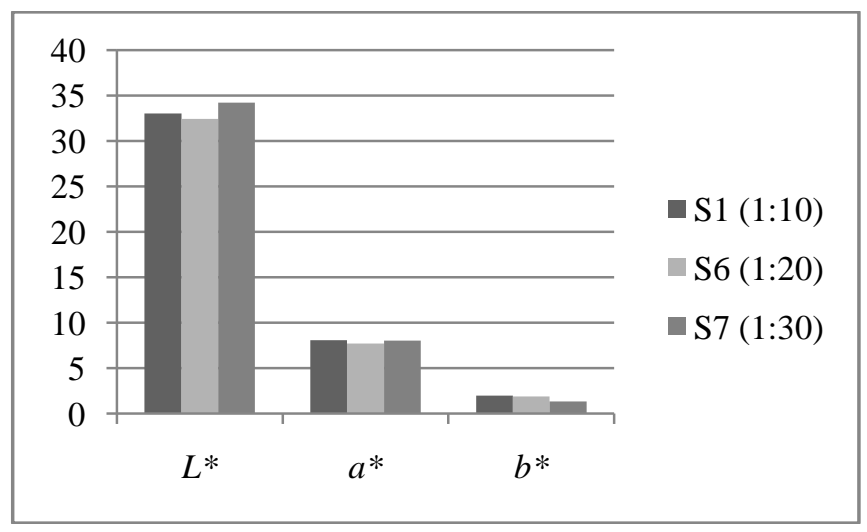

Fig 4: Effect of liquor ratio (M: L)

\subsubsection{Effect of Temperature}

Temperature had almost same type of effect like electrolyte. Figure 4 represents that a higher temperature increases the $L^{*}$ value and also the strength\% (Table 5). Redness $\left(a^{*}\right)$ of the shade was increasing with temperature and yellowness was decreasing. Or in other words blueness was increasing. DRK and DBK fixation was clearly increased in higher temperature, though DYK fixation was decreasing. 


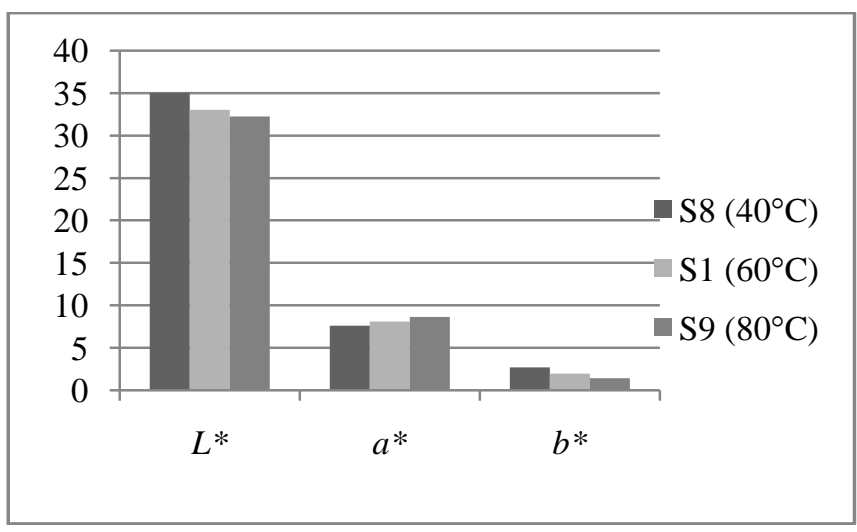

Fig 5: Effect of temperature $\left({ }^{\circ} \mathrm{C}\right)$

May be it is because of the reactivity of the dyes which increases with temperature. The data from all tables and graphs indicates that DYK has a greater tendency of hydrolysis among these three.

\section{CONCLUSIONS}

In conclusion following observations can be pointed out-

1. Electrolyte, alkali and temperature positively influence on the depth of the shade. 1:20 liquor ratio was found suitable to gain better color value.

2. Among the three dyes DRK was positively influenced by the parameters. DYK may have greater tendency to be hydrolyzed.

3. Allover dye uptake order due to the increase of parameter values: DRK $>$ DBK $>$ DYK.

4. For matching a reddish shade, increasing temperature or electrolyte amount can help in matching the shade easily. But in case of a greenish shade, increase of those will not be fruitful.

5. Increase of bluish tone can be possible by increasing electrolyte, alkali or temperature.

\section{ACKNOWLEDGEMENTS}

The author gratefully acknowledges the support from Clariant (Bangladesh) Ltd. and Impress-Newtex Composite Textile Ltd, Mirzapur, Tangail, Bangladesh.

\section{REFERENCES}

[1]. M. N. Miljkovic, V. B. Ignjatovic, A. R. Zarubica, "Influence of Different Parameters on Dyeing of Knitting Material with Reactive Dyes" Facta Universitatis; Physics, Chemistry and Technology; Volume: 5, No: 1, 2007, PP: 6984.

[2]. Saeed Q., Bhatti, I.A., Zuber, M., Nosheen, S., Zia, M.A. , Abbas M., "Study of Application of Mono azo Reactive Dyes on Cotton by Exhaust method and Printing Properties" International Journal of Basic \& Applied Sciences; Volume: 2, No: 6, 2012; PP:191-197.
[3]. Dalal, M. M., Desai, R. K. "Dyeing Effects of Bifunctional Reactive Dyes on Knitted Cotton Fabrics" American Dyestuff Reporter; Volume: April,1996, PP: 22-25. [4]. Sultana, R., Uddin, Z. M. "Compatibility Testing of Reactive Dyes" Journal of Mechanical Engineering; Volume: ME38, 2007, Page: 61-64.

[5]. Arzu, H. F. M., Rahman, M. M. "Effect of process parameters on cotton fabric dyeing with reactive dye especially on Green Color" Pakistan Textile Journal, Volume: April, 2009.

[6]. Shenai, A. V. "Technology of Textile Processing Volume II" Chemistry of Dyes and Principles of Dyeing; Sevak Publications, 1993, PP: 527.

[7]. J. R. Aspland, "Textile dyeing and coloration" American Association of Textile Chemists and Colorist, 1997, PP: 132.

\section{BIOGRAPHIES}

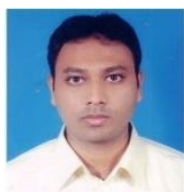

The author had completed his graduation from College of Textile Technology, University of Dhaka. His area of interest is textile wet process. He has about five years of teaching experiences. 